\title{
A study on the Perception of Factors Influencing Gender Pay Gap in the Information Technology Industry of Kerala
}

\author{
ArchanaThulaseedharan ${ }^{1}$, Dr.Vinith Kumar Nair ${ }^{2}$ \\ ${ }^{l}$ (Dept. of Management, Bishop Jerome Institute, India) \\ ${ }^{2}$ (Dept. of Management, TKM Institute of Management, India)
}

\begin{abstract}
Gender pay gap has been part of scholarly discussions for quite some time. In our study we highlight the perception of employees of Information Technology on gender pay gap and the factors influencing the same in the region of Kerala, in which, not many studies have been conducted. Through a focus group discussion, the data was collected, converted into quantitative and then analyzed through factor analysis. We found out that the majority of the respondents perceived gender pay gap in their organizations. Our study also found out that,the respondents perceived, Working for long hours, Bargaining power, Networking with Superiors, Projecting Oneself, Gender Discrimination as the main factors that influences the gender pay gap.
\end{abstract}

Keywords:- Information Technology, Gender, Gender Pay Gap, Perception

\section{INTRODUCTION}

In spite of a substantial decline in the gender wage gap since the 1960s, women still earn significantly lower wages than men. There is an ample improvement in terms of education, labor market qualifications, experience etc. over the past 40 years. Moreover, technological change and industrial restructuring has led to an increased demand for white-collar workers. However, empirical evidence from an international meta-analysis indicates that men with similar labor market qualifications as women earn a wage premium of $25 \%$ on average and that this varies considerably between countries. [1]

According to the report by ILO 2009 report, the progress in decreasing the gender pay gap is very slow in Europe and central Asia. In the United States the pay gap persistent has declined only slightly. The report by ITUC 2008 report shows that across African countries women are engaged more in informal and unpaid employment and due to this there is little official data available on the pay gap.

Now why this gender gap? According to ILO, in a broad-spectrum, there are two main reasons for the pay gap; direct gender discrimination in labor markets and occupational segregation direct discrimination occurs when people who possess the same level of educational attainment and work experience are treated differently because of their gender. This can be different pay levels for the same work or different job requirements for the same pay level. According to the ILO 2009 report, even though women represent 40.4 percent of the worldwide workforce, the proportion is not across the various sectors. Service sector seems to be the most preferred with 46.3 percent of women employees, followed by agriculture sector with 35.4 percent employees while only 18.3 percent in the industrial sector, compared to 26.6 percent of employed men.

Despite the efforts of the government by introducing several laws to prohibit inequalities or discrimination against women workers, there still exists a wide gender pay gap in India. This arises the question: Does the so called glass ceiling still exists in Indian workplaces? Data shows yes and hence the objective of the study is to find out the perception of glass ceiling with respect to pay and the factors that influences the same.Insipte of the efforts by corporate and government to reduce the pay gap, the reality is our corporates are not free from this. It's not the case with Indian corporates it's applicable to all most all the countries. Hence it's a serious concern and since there are not many studies conducted with IT sector Kerala on pay gap studies, we decided to choose the IT employees of Kerala. The paper is divided into five parts. We started with theoretical framework followed by literature review, objectives, findings and discussion and conclusion.

\section{THEORETICAL FRAME WORK}

Gender pay gap measures the difference in earnings between women and men in a labor market. Different theories have been devised to explain the gender pay gap .The most prominent one is the Human capital model and the labor discrimination model. Studies by Becker, MincerPolachek (1974)[2].have proved that factors like education, training, experience are contributors to productivity which in turn will affect the wages.According to their study, women accumulate less human capital and hence less wages compared to men. This is because of the traditional division of labor within the family and voluntary choices exercised by women to invest less in human capital. This alone need not be the reason for pay gap.Discrimination in the labor market can be explained as the result of employer's tastes or preference. Some employers have a taste for discrimination against women workers and thus, hiring women imposes an additional psychic cost on them. 
[3]In this paper, we also consider an important theory on gender pay gap that has roots in the psychological differences in the behavior of men and women. Studies also argue that a powerful cause of women's disadvantage is that they tend to have a lower opinion of themselves than men so do not ask their bosses for what they want and passively accept wage offers rather than bargain for better conditions. [4]

\section{LITERATURE REVIEW}

The gender gap in wage is not a contemporary issue, but has long been an issue that has attracted both political and scholarly discussions. There appears to be inequity in pay in corporate India, fifty seven percent women think that they need to work harder than men to prove their competence. Having children tend to result in higher wages for men, whether they're straight or gay, married or partnered. Women are not so fortunate; Most mothers make less than childless women, A study conducted on US Grads shows that $45 \%$ said female grads would face some form of gender bias at world,13\% said female grads would find it more difficult to network,33\% said gender would affect female grads' pay, but only $13 \%$ believed that gender bias would affect them personally, $7 \%$ believed that networking would be harder for them personally, only $27 \%$ believed that gender would affect their own pay.[5]

A study on wages earned by male employees and female employees of Netherland [6] shows that despite major improvements in women's labor market attachment, women still earn considerably less than men. It's found that female executives tend not to reap the rewards of strong corporate performance. Data shows that women's bonuses stay flat how well the company is doing in contrast to the wages of the male counterpart. International research shows that although the gap in characteristics between men and women is diminishing, changes in the wage structure counteract this change. A study that focuses on whether this 'swimming upstream' phenomenon is also playing a role in the rather slow convergence between male and female wages in the Netherlands shows that te that this is not the case; most of the changes in the Dutch wage structure have been rather favorable to women. The lacking convergence in wages has to be explained from the fact that despite the favorable changes, the Dutch wage structure still contains a considerable implicit gender bias.

A Research in India to explore the impact of economic liberalization on the earning gap during the period of 1987-1999 shows that the gender earnings gap had narrowed considerably between these two years, for all earnings deciles and for all education cohorts. The narrowing of the earnings gap can be attributedlargely to a sharp increase in the returns to the labor market experience of women. [7]

There is no such single cause for gender pay gap.Barriers in hiring Sexual harassment and Unequal access to promotion are all hindering factors that contribute to less pay for women .Research suggests that discrimination, occupation segregation and undervaluation of women work are the major causes of gender pay gap [8]More recently institutional and situational variables arealso used.[9]The study conducted by the government $t$ of Australia has found out that there is gender pay gap of $17.5 \%$ and the factors are discrimination, the different balance of paid and unpaid work that women and men undertake in their lifetime, the different industries in which women work compared to men and the under-valuationof the occupations in which women are largely employed (e.g. in caring and personal service roles) the way pay is set. [10]

\section{OBJECTIVES OF THE STUDY}

Most of the studies quoted above showed that there is gender pay gap. But very few studies have done in Kerala. Hence we took Kerala and we selected the IT industry which is one of the promising industries of Kerala. Theobjective of our study was to find out,the perception ofthe existence of gender pay gap in the IT sector of Kerala. Our focus was then to find out the perception of thefactors that influence gender pay gap. We also identified the important factors perceived by the respondents as the one that influences the gender pay gap

\section{METHODOLOGY}

This research was undertaken in 15IT organizations of techno park Trivandrum through Focus Group Discussion with20 employees. There were $10 \mathrm{HR}$ managers and 10 IT employees. The break up was as follows Ten HR managers with 10-15 years of experience, Two employees from top level Six from mid-level and Two from entry- level. The discussion was done to find out the various perspectives on the causes of gender based pay.

After this, the data from the discussion was combined and then the opinions were quantified using a 5 point likert scale. Wereduced the data, as well as, removed some redundant variables, through factor analysis, which helped us to remove variables (highly correlated) from the data file, perhaps replacing the entire data file with a smaller number of uncorrelated variables.

We started with descriptive statistics of all the variables and KMO and Bartlett test was done to measure the sampling adequacy 
Next in the Total variance chart the variance explained by the initial solution, extracted components, and rotated components is displayed. This first section of the table shows the Initial Eigenvalues. The total column gives the eigenvalue, or amount of variance in the original variables accounted for by each component .The $\%$ of Variance column gives the ratio, expressed as a percentage, of the variance accounted for by each component to the total variance in all of the variables. The Cumulative $\%$ column gives the percentage of variance accounted for by the first $\mathrm{n}$ components.

In the initial solution, there are as many components as variables, and in a correlations analysis, the sum of the eigenvalues equals the number of components. Once the factors are extracted next a rotation of components were done.Rotation maintains the cumulative percentage of variation explained by the extracted components, but that variation is now spread more evenly over the components. The large changes in the individual totals suggest that the rotated component matrix will be easier to interpret than the unrotated matrix. We used Varimaxrotation an orthogonal rotation of the factor axes to maximize the variance of the squared loadings of a factor (column) on all the variables (rows) in a factor matrix, which has the effect of differentiating the original variables by extracted factor. This will help us to derive either large or small loadings of any particular variable. A varimax solution yields results which makes it as easy as possible to identify each variable with a single factor. This is the most common rotation option. The scree plot helps to find out the optimal number of components. The eigenvalue of each component in the initial solution is plotted. Generally, you want to extract the components on the steep. The components on the shallow slope contribute little to the solution. Thus through factor analysis we identified the major factors that influences pay. There were totally nineteen statements from which we identified five factors.

\section{FINDINGS AND DISCUSSION}

The discussion data was aggregated and to identify the representative constructs through factor analysis we could describe the variability among the nineteen observed, correlated variables in terms of a potentially six unobserved variables or factors.

\subsection{Findings 1}

The results of the perception of the Male respondents showed that $42 \%$ Strongly Agree, $36 \%$ Agree and $22 \%$ agree to some extent, that there is gender pay gap among the IT employees of Kerala. Among the Female respondents, $68 \%$ strongly agree $28 \%$ agree and $4 \%$ agree to some extent that there is gender pay gap.

The results of the descriptive statistics for the causes of Gender pay Gap as displayed TABLE 1, Quality of output and, Bargaining power both with a Mean 4.50 are rated as the most important factor)that causes gender pay gap. This was followed by Quality of output (Mean 4.40) and Working for long hours (Mean 4.35).

One respondent commented "working for long hours will create an impression among the superiors that the employee hard working. May be there is no extra output. Note, may be in many times it happens like that."

The other factors which the respondents rated high are men are available after office hours with a mean of 4.25 and negotiating influences the pay again with a mean of 4.25 .

Another respondent commented "Usually men work for long hours, I mean sit in the office after the office hours.Doesnt mean that they are doing extra work compared to men I finish and leave he continue sitting there without any extra out".

Then the male responded commented "It definitely helps me to have an informal relation with my other colleagues as well as networking with my boss. And many of the ideas are generated during this discussion".

Table1 Descriptive Statistics of FactorsInfluencing gender pay gap

\begin{tabular}{|l|l|l|l|}
\hline Descriptive Statistics & Mean & $\begin{array}{l}\text { Std. } \\
\text { Deviation }\end{array}$ & Analysis N \\
\hline Variables & 4.3500 & .67082 & 20 \\
\hline Working for long hours & 3.9000 & .85224 & 20 \\
\hline Sits in the office after office hours & 2.0000 & .85840 & 20 \\
\hline Women cannot sit after office hours & 3.7500 & .91047 & 20 \\
\hline Even if the work is over men stay back at office & 4.2500 & .63867 & 20 \\
\hline Men are available after office hours & 4.5000 & .51299 & 20 \\
\hline Bargaining Power Influences Pay & 4.2500 & .71635 & 20 \\
\hline Negotiating with superiors Influences pay & 4.1000 & .64072 & 20 \\
\hline People who ask will get more salary & 3.6500 & .74516 & 20 \\
\hline Networking influences pay & 3.7000 & .73270 & 20 \\
\hline Good relation with boss increases pay & & \\
\hline
\end{tabular}


A study on the Perception of Factors Influencing Gender Pay Gap in the Information Technology ...

\begin{tabular}{|l|l|l|l|} 
Interpersonal relation with boss increases pay & 3.5500 & .99868 & 20 \\
\hline Impression management influences pay & 4.0000 & .64889 & 20 \\
\hline Men work long hours which enhances impression and pay & 3.9000 & .71818 & 20 \\
\hline Men is good in impression management and enhances pay & 3.8500 & .58714 & 20 \\
\hline Quality of output enhances pay & 4.5000 & .51299 & 20 \\
\hline Whatever be the strategy quality matters lot & 4.4000 & .50262 & 20 \\
\hline Gender discrimination influences pay & 2.7000 & .73270 & 20 \\
\hline Women will not get high pay & 3.7500 & .71635 & 20 \\
\hline Whatever be the quality gender influences pay & 3.0500 & .60481 & 20 \\
\hline
\end{tabular}

\subsection{Findings 2}

KMO test was done to measure the proportion of the variance in the 19 variables that might be caused by the factors. High values (close to 1.0) generally indicate that a factor analysis may be useful with the data. If the value is less than 0.50 , the results of the factor analysis probably won't be very useful.The KMO Result of .318 (TABLE 2) shows less compact and would yield less distinct and less reliable factors.Bartlett's Tests would indicate whether the variables are unrelated and therefore unsuitable for structure detection. Small values (less than 0.05) of the significance level indicate that a factor analysis may be useful with the data.The Bartlett's test ofspherecity of our study (Table 2$)$ was $.000(\mathrm{p}<.005)$ and hence was highly significant

Table 2: KMO and Bartlett's Test

\begin{tabular}{|l|l|r|}
\hline \multicolumn{3}{|c|}{ KMO and Bartlett's Test } \\
\hline Kaiser-Meyer-Olkin Measure of & .318 \\
\hline \multirow{3}{*}{$\begin{array}{l}\text { Bartlett's Test of } \\
\text { Sphericity }\end{array}$} & $\begin{array}{l}\text { Approx. Chi- } \\
\text { Square }\end{array}$ & 453.111 \\
\cline { 2 - 3 } & df & 171 \\
\cline { 2 - 3 } & Sig. & .000 \\
\hline
\end{tabular}

\subsection{Findings 3}

The total variance chart (TABLE 3) Shows that only 5 factors in the initial solution have eigenvalues greater than one. If a factor has Eigenvalue less than 1.0, it explains less variance and is rejected. SPSS default is to keep any factor with an Eigene value larger than 1.0.The eigenvalue for a given factor measures the variance in all the variables which is accounted for by that factor. The ratio of eigenvalues is the ratio of explanatory importance of the factors with respect to the variables. If a factor has a low eigenvalue, then it is contributing little to the explanation of variances in the variables and may be ignored as redundant with more important factors. Eigenvalues measure the amount of variation in the total sample accounted for by each factor.The first Eigene value was 6.693 followed by second factor with a eigenvalue of 3.740, third factor with a eigenvalue of 2.397 , fourth factor with a eigenvalue 1.866 and fifth factor with a eigenvalue of 1.294. As the theory predicts the first factor has the largest value which explains the greatest amount of variance. It then lists the percent of the variance accounted for by this factor (eigenvalue divided by the total number of variables) and this was followed by a cumulative percent. In our study, together the five factors accounted for $84 \%$ of the originality in variables. This means that $84 \%$ of the perceptions of respondents are explained through five factors

\subsection{Findings 4}

A scree plot was obtained to conform the five factors. As shown in Fig 1 below, five to six factors would be appropriate for explaining the factors. 


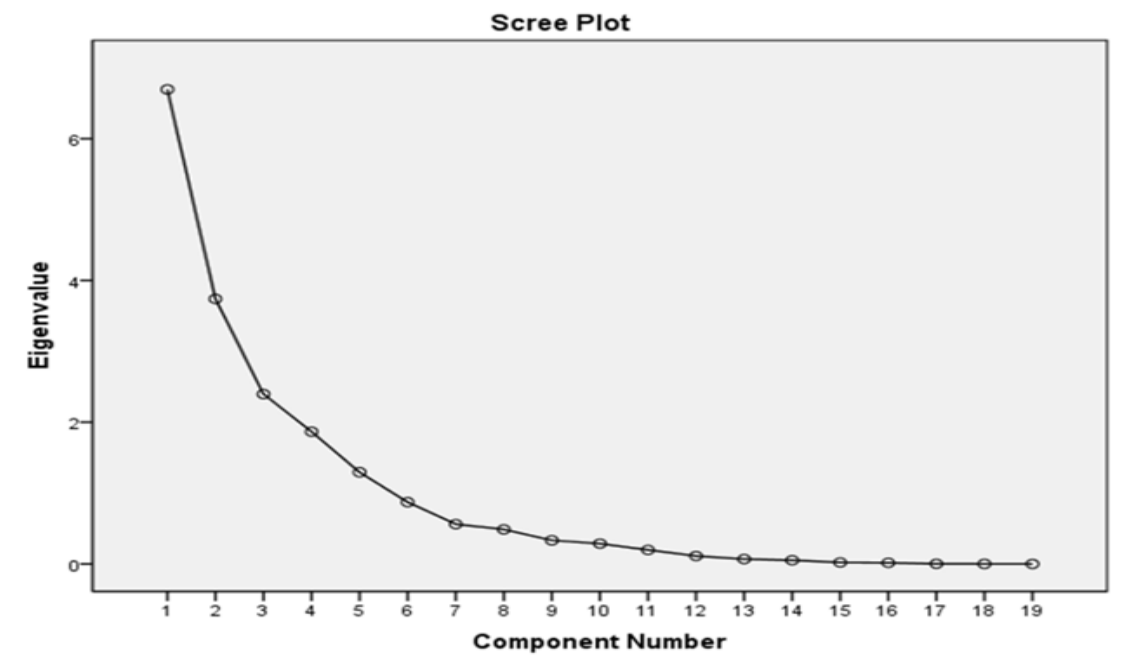

Figure 1: Scree Plot

Table 3: Total variance

\begin{tabular}{|c|c|c|c|c|c|c|c|c|c|}
\hline \multicolumn{10}{|c|}{ Total Variance Explained } \\
\hline \multirow[b]{2}{*}{$\begin{array}{l}\text { Compon } \\
\text { ent }\end{array}$} & \multicolumn{3}{|c|}{ Initial Eigenvalues } & \multicolumn{3}{|c|}{ Loadings } & \multicolumn{3}{|c|}{ Loadings } \\
\hline & Total & $\begin{array}{c}\% \text { of } \\
\text { Variance }\end{array}$ & $\begin{array}{c}\text { Cumulativ } \\
\text { e } \%\end{array}$ & Total & $\begin{array}{c}\% \text { of } \\
\text { Variance }\end{array}$ & $\begin{array}{c}\text { Cumulativ } \\
\mathrm{e} \%\end{array}$ & Total & $\begin{array}{c}\% \text { of } \\
\text { Variance }\end{array}$ & $\begin{array}{c}\text { Cumulativ } \\
\text { e } \%\end{array}$ \\
\hline 1 & 6.696 & 35.240 & 35.240 & 6.696 & 35.240 & 35.240 & 4.751 & 25.005 & 25.005 \\
\hline 2 & 3.740 & 19.683 & 54.923 & 3.740 & 19.683 & 54.923 & 3.336 & 17.557 & 42.562 \\
\hline 3 & 2.397 & 12.614 & 67.537 & 2.397 & 12.614 & 67.537 & 3.180 & 16.735 & 59.297 \\
\hline 4 & 1.866 & 9.820 & 77.357 & 1.866 & 9.820 & 77.357 & 2.556 & 13.453 & 72.750 \\
\hline 5 & 1.294 & 6.809 & 84.166 & 1.294 & 6.809 & 84.166 & 2.169 & 11.416 & 84.166 \\
\hline 6 & .872 & 4.589 & 88.755 & & & & & & \\
\hline 7 & .561 & 2.954 & 91.708 & & & & & & \\
\hline 8 & .487 & 2.562 & 94.270 & & & & & & \\
\hline 9 & .333 & 1.753 & 96.023 & & & & & & \\
\hline 10 & .286 & 1.507 & 97.530 & & & & & & \\
\hline 11 & .197 & 1.038 & 98.568 & & & & & & \\
\hline 12 & .112 & .592 & 99.160 & & & & & & \\
\hline 13 & .068 & .360 & 99.520 & & & & & & \\
\hline 14 & .052 & .272 & 99.792 & & & & & & \\
\hline 15 & .021 & .109 & 99.901 & & & & & & \\
\hline 16 & .016 & .084 & 99.985 & & & & & & \\
\hline 17 & .002 & .010 & 99.995 & & & & & & \\
\hline 18 & .001 & .004 & 99.999 & & & & & & \\
\hline 19 & .000 & .001 & 100.000 & & & & & & \\
\hline
\end{tabular}

\subsection{Findings 5}

Next we obtained the component matrix and rotated component matrix.(TABLE 4 ) Extraction method was done through principal component analysis in which the Factor weights are computed in order to extract the maximum possible variance, with successive factoring continuing until there is no further meaningful variance left. Using principal component analysis 5 factors were extracted.

Table 4 Rotated component matrix

\begin{tabular}{|l|l|l|l|l|l|}
\hline Rotated Component Matrix & \multicolumn{5}{l|}{ Component } \\
\cline { 2 - 7 } Variables & 1 & 2 & 3 & 4 & 5 \\
\hline Sits in the office after officehours & .895 & -.094 & -.225 & .202 & .038 \\
\hline People who ask will get more salary & .814 & .255 & -.196 & -.226 & -.168 \\
\hline Interpersonal relation with boss increases pay & .814 & .324 & .196 & -.154 & -.103 \\
\hline
\end{tabular}


A study on the Perception of Factors Influencing Gender Pay Gap in the Information Technology ...

\begin{tabular}{|l|l|l|l|l|l|} 
Networking influence spay & .751 & .175 & .282 & -.325 & .044 \\
\hline Negotiating with superiors influences pay & .741 & .465 & -.278 & -.109 & -.242 \\
\hline Men are available after office hours & -.106 & -.819 & .245 & .324 & .065 \\
\hline Whatever be the strategy quality matters lot & .185 & .809 & .011 & .270 & .334 \\
\hline Women cannot sit after officehours & .047 & .693 & .463 & .173 & -.153 \\
\hline Quality of output enhances pay & -.608 & -.666 & .100 & .018 & .219 \\
\hline Evenif the work is over men stay backoffice & .445 & .627 & .135 & .136 & -.481 \\
\hline Projecting oneself influencespay & -.223 & -.041 & .870 & .138 & .143 \\
\hline Women will not get high pay & -.043 & -.060 & .858 & -.297 & -.099 \\
\hline Goodrelation with boss increases pay & .174 & .049 & .678 & -.265 & -.140 \\
\hline Bargaining power influences pay & -.167 & .202 & -.132 & .897 & .031 \\
\hline Working for long hours & -.565 & -.032 & -.110 & .711 & .046 \\
\hline Genderdiscrimination influences pay & .300 & -.215 & -.518 & .666 & -.298 \\
\hline $\begin{array}{l}\text { Men isgood in impression management which } \\
\text { enhances pay }\end{array}$ & .004 & -.056 & .075 & -.086 & .942 \\
\hline $\begin{array}{l}\text { Men work long hours which enhances impression } \\
\text { and pay }\end{array}$ & .523 & -.173 & .413 & -.112 & -.566 \\
\hline Whatever be the quality gender influences pay & -.323 & -.373 & -.406 & .382 & .547 \\
\hline
\end{tabular}

Once the factors have been selected, the next step is to rotate them. Rotation is needed because the original factor structure is mathematically correct but is difficult to interpret. The goal of the rotation is to achieve what is called simple structure that is high factor loadings on one factor and low loading factors on all others. Factor loadings vary between +1.0 to -1.0 and indicate the strength of relationship between a particular variable and a particular factor in a way similar to correlation. We used Varimax Rotation with Kaizer normalization. Rotations converged in 8 iterations. We then derived the items coming under each factor. The rotated component matrix helps you to determine what the components represent.

As shown in TABLE 5,the first component is highly correlated with the variables 1)Sits in the office after office hours, 2)People who ask will get more salary, 3)Interpersonal relation with boss increases pay, 4)Networking influence pay5)Negotiating with superiors influence pay and hence we identified the factor as Networking with boss. The second component is highly correlated with variables1) men are available after office hours,2) whatever be the strategy quality matters lot,3) women cannot sit after officehours,4)quality of output enhances pay,5)even if the work is over men stay back office.Hence we developed the factor working for long hours. The third component is highly correlated with three variables 1) projecting oneself influences pay, 2) women will not get high pay,3)good relation with boss increases pay. The fourth component is highly correlated with the three variables 1)bargaining power influences pay,2)Working for long hours,3)Gender discrimination influences pay. Among this the first variable bargaining power influence is a better representative and hence we developed bargaining power as the fourth factor that influences pay. The final and fifth component has yet another three variables with high correlation. They are1) male employees create good impression which enhances pay, 2) Male employees work long hours enhances impression and pay, 3) Whatever be the quality gender influences pay

Table 5 Exploratory analysis of perception of Factors Influencing gender pay gap

\begin{tabular}{|l|l|l|}
\hline $\begin{array}{l}\text { Variable } \\
\text { Number }\end{array}$ & Constructs and items & Factor Loading \\
\hline Factor: Networking with Boss(Eigenvalue:6.696) & 0.895 \\
\hline 2 & Sits in the office after office hours & 0.814 \\
\hline 8 & People who ask will get more salary & 0.814 \\
\hline 11 & Interpersonal relation with boss increases pay & 0.751 \\
\hline 9 & Networking influence pay & 0.741 \\
\hline 7 & Negotiating with superiors influence pay & 0.819 \\
\hline Factor: Working long hours(Eigenvalue:3.740) & 0.809 \\
\hline 5 & Men are available after office hours & 0.693 \\
\hline 16 & Whatever be the strategy quality matters lot & 0.666 \\
\hline 3 & Women cannot sit after office hours & 0.627 \\
\hline 15 & Quality of output enhances pay & 0.87 \\
\hline 4 & Even if the work is over men stay back office & 0.858 \\
\hline Factor: Impression Management/Projecting Oneself(Eigenvalue:2.397) & 0.678 \\
\hline 12 & Projecting oneself influencespay & \\
\hline 18 & Women who doesn't project oneself will not get high pay & \\
\hline 10 & Good relation with boss increases pay & \\
\hline
\end{tabular}


A study on the Perception of Factors Influencing Gender Pay Gap in the Information Technology ...

\begin{tabular}{|l|l|l|}
\hline \multicolumn{2}{|l|}{ Factor: Bargaining Power(Eigenvalue1.866) } & 0.897 \\
\hline 6 & Bargaining power influences pay & 0.711 \\
\hline 1 & Working for long hours & 0.666 \\
\hline 17 & Gender discrimination influences pay & 0.942 \\
\hline Factor: Gender Discrimination(Eigenvalue:1.294) & 0.566 \\
\hline 14 & Male employees create good impression which enhances pay & 0.547 \\
\hline 13 & Male employees work long hours enhances impression and pay & \\
\hline 19 & Whatever be the quality gender influences pay & \\
\hline
\end{tabular}

\section{CONCLUSION}

Pay is one of the most important factors that motivate an employee to work. Gender pay gap, even though is not a new concept has become important because of its inexorable presence in all the corporates. Indian corporates are also of no exception. There are many studies conducted on gender pay gap. The present study focused on finding out the perception of factors causing gender pay gap in the IT industry of Kerala.We decided to go for an exhaustive focus group discussion so that we could explore deeply the perception of employees on factorsthat cause the pay gap. The study is thus different because we made an attempt at IT employees of Kerala where very few studies have conducted on the same. The focus group discussion data was converted into quantitative data using a five point likert scale and then analyzed through factor analysis. From the nineteen unobserved data we have derived five main factors. We selected Networking with Boss as the first which is highly correlated with the variables 1)Sits in the office after office hours, 2)People who ask will get more salary, 3)Interpersonal relation with boss increases pay, 4)Networking influence pay5)Negotiating with superiors influence pay and hence we identified the factor as Networking with boss. The second component is highly correlated with variables1) men are available after office hours,2) whatever be the strategy quality matters lot,3) women cannot sit after officehours,4)quality of output enhances pay,5)even if the work is over men stay back office. Hence we developed the factor working for long hours. The third component is impression management which highly correlated with three variables 1 ) projecting oneself influences pay, 2) women will not get high pay,3)good relation with boss increases pay. The fourth component is highly correlated with the three variables 1)bargaining power influences pay,2)Working for long hours,3)Gender discrimination influences pay. Among this the first variable bargaining power influence is a better representative and hence we developed bargaining power as the fourth factor that influences pay. The final and fifth component we identified is gender discrimination which has yet another three variables with high correlation. They are1) male employees create good impression which enhances pay, 2) Male employees work long hours enhances impression and pay, 3) whatever be the quality gender influences pay. Thus the study shows that the respondents perceived the existence of pay gap and according to them, the above said factors influences the pay gap. The study will be more useful if it can be extended to find out the perception of a large number of employees. However, mere perceptions may be inadequate; hence there isa much great scope for studying the real causes of gender pay gap and the various measures that can be adopted to overcome this issue.

\section{REFERENCES}

[1]. Weichselbaumer (2007) Market Orientation and Gender Wage Gaps. An International Study Economics Series, Institute for Advanced Studies

[2]. Gary S. Becker (1964, 1993, 3rd Ed.). Human Capital: A Theoretical and Empirical Analysis, with Special Reference to Education. Chicago, University of Chicago Press. ISBN 978-0-226-04120

[3]. 3Mincer, Jacob and Polachek, Solomon. "Family Investment in Human Capital: Earnings of Women," Journal of Political Economy, University of Chicago Press, vol. 82(2), 1974, S76-S108, Part II

[4]. Linda Babcock \& Sara Laschever, Women Don't Ask: Negotiation and the Gender Divide (eBook ISBN: 9781400825691, W Princeton university press Cloth 2003)

[5]. L.Clara, S.Rafael, A.Baumle, and A.Kulich, Harvard Business Review; 88(9), Sep2010, 22-27,

[6]. Blau, Lawrence Kahn The Gender Pay Gap:Have women gone as far as they can? Academy of Management Perspectives February 2007, pp.7-23

[7]. Bhaumika Charkrabarty (2008) Does move to market have an impact on earnings gap across Gender? Some evidence from India, Applied Economics Letters, 2008, 15, 601-605

[8]. Rose and Hartman (2004), The long term gender, Challenge, ME Sharpe, 47(5) Sep-Oct 2004, pp. 30-50

[9]. Fortin, Lemieux (1998). "Rank Regressions, Wage Distributions, and the Gender Gap," Journal of Human Resources, University of Wisconsin Press, vol. 33(3), pages 610-643.

[10]. Australian Bureau of Statistics (ABS), Cat. No. 6302.0, Average Weekly Earnings - Trend data, May 2012 (released 17.08.12). 